\title{
Electrochemical Determination of Methyldopa by Graphene Quantum Dot / 1-butyl-3-methylimidazolium hexafluoro phosphate Nanocomposite Electrode
}

\author{
Afsaneh L. Sanati ${ }^{1}$, Farnoush Faridbod ${ }^{1,2, *}$ \\ ${ }^{1}$ Center of Excellence in Electrochemistry, School of Chemistry, College of Science, University of \\ Tehran, Tehran, Iran \\ ${ }^{2}$ Biosensor Research Center, Endocrinology \& Metabolism Molecular-Cellular Sciences Institute, \\ Tehran University of Medical Sciences, Tehran, Iran \\ *E-mail: faridbodf@khayam.ut.ac.ir
}

doi: $10.20964 / 2017.09 .71$

Received: 31 May 2017 / Accepted: 23 July 2017 / Published: 13 August 2017

Methyldopa is one the important catecholamines used for treatment of high blood pressure. In this study, a nanocomposite electrode was made using graphene quantum dots (GQD) and 1-butyl-3methylimidazolium hexafluorophosphate $\left(1 \mathrm{~B} 3 \mathrm{MIPF}_{6}\right)$ in a carbon paste matrix (GQD/1B3MIPF $/$ /CPE). The used GQD was synthesized and characterized using transmission electron microscopy (TEM). The electro-oxidation behavior of Methyldopa was investigated on the surface of GQD/1B3MIPF 6 /CPE and finally it was used as a working electrode for the electrochemical determination of Methyldopa in some pharmaceutical and biological samples. The results showed an improvement of $~ 3.2$ times in electro-oxidation peak of methyldopa in a dynamic linear range of 0.04$750.0 \mu \mathrm{M}$ (limit of detection $0.01 \mu \mathrm{M}$ ).

Keywords: Graphene quantum dots, Methyldopa, Carbon paste electrode, Voltammetry

\section{FULL TEXT}

(C) 2017 The Authors. Published by ESG (www.electrochemsci.org). This article is an open access article distributed under the terms and conditions of the Creative Commons Attribution license (http://creativecommons.org/licenses/by/4.0/). 